\title{
Vulnerabilities of Human Kind in Samuel T. Coleridge's The Rime of the Ancient Mariner: A Modernist FormalistPreview
}

\author{
Marwan A. Hamdan
}

\begin{abstract}
The Rime the Ancient Mariner. Modern man's juxtaposed vulnerabilities and calamities constitute significant thematic contributions tothe critical appreciation of the poem. Using various modernist artistic techniques and mechanisms, Coleridge stresses a variety of questions about his mariner as a modern man who gets lost amidst a stormy life. The chaotic nature is Coleridge's largest crucible of human experiences and futilities. Also, spiritual and earthly implications of modern man are mirrored in the wavy world of the poem. Alienation, solitude, absurdity, and fragmentation are basic passions and pain-driving powers, on their theoretical, practical, epistemological and artistic grounds. The paper also examines the modernist formalistic techniques in which the poet depicts modern man's reactions to redeem himself and transform to a better catharsized man.
\end{abstract}

Keywords:-Coleridge, futilities, modernism, techniques, sinning, punishment, and redemption.

\section{INTRODUCTION}

The Rime the Ancient Mariner tells the story of the return of an old mariner from a long trip charged with hardships after killing albatross; a curse falls on the ship. As a result, every mariner dies of thirst and drought. The old mariner beholds another ship sailing away from him and when he wants to scream his mouth is dry and frozen. In addition, the ship is not but a ghost ship led by two spirits: life and death. All the crew die and the mariner survives alone and feels lonely till he realizes repentance and discovers the value of every living thing; he attains forgiveness and salvation. The mariner narrates his tale about his drastically dramatic voyage to a wedding guest. The wedding guest wants to go to a wedding, which cannot restrain him from the tale of the old mariner. In this context, the poet Coleridge transfers his readers to a modernist enchanted world of fantasy that lies between dream and reality in a poem rich with music, alliteration, anaphora, and antithesis in a modernist sense. The poem raises modernist questions on intellectual, theoretical, political, ideological, and philosophical grounds that the mariner tries to find answers.

In fact, the poem is one of the most significant poems in the Romantic era. Yet, it embodies a set of poetic modernist manifestations. Coleridge's critics have pointed out that the first theme that characterizes the poem is pride; a modernist renewed impression. In this regard, Coleridge says,

I looked to heaven, and tried to pray;

But or ever a prayer had gushed,

A wicked whisper came, and made

My heart as dry as dust.

(IV, L. 21-24)

The old mariner does not expect that killing the albatross will bring drought, misery, and death to the ship. Rather, the mariner, out of his miscalculation, thinks that his crew can manage their voyage without this bird, whose arrival coincides with a lot of good luck. However, shooting the albatross raises the question of the reason that makes the mariner kill the bird. Obviously, the mariner has acted so out of his sole sense of pride, "For all averred, I had killed the bird/That made the breeze to blow" (II, L. 11-14). Despite seeming a social man before launching his fateful voyage, the mariner travels into his mysterious world in search of the lost souls like his. This action raises the theme of isolation; when death chases the sailors, the mariner remains alive in death. The world around him is very wide, but the whole world seems like burden that dazzles his eyes, and he incredibly stays lonely. Based on such a theme, the potential modernist tone arises from the exciting and entertaining poetic narrative that bears a deep human significance. This modernist tone dominates the poem, not only in the light of its thematic moral significance, which looks unconvincing at times, but also in the exclusive poetic details charged with juxtaposed hilarious dark images that make the poem modernist.

\section{The Modernist Poetic Discourse inThe Rime of the Ancient Mariner:}

Modernism in literature, mainly poetry, means introducing new idea, theme, technique, and character in a cultural human tendency. In Coleridge's poem, there are new juxtaposed ideas and themes manifested in 
fragmentation, vulnerabilities, loneliness, alienation and loss. Such modernist features imply an absurd reflection on the mariner and his original sin. Coleridge's story of the mariner implies "absurd and constructive" aspects in a mythical sense similar to "Sisyphus" that suffers inescapableloneliness (Skemman, 2016). The mariner survives alone and lonely:

Alone, alone, all, all alone,

Alone on a wide wide sea!

And never a saint took pity on

My soul in agony.

Here, Coleridge keeps describing the mysterioussufistmoments that surround the silent ship in his own magical words. Moreover, the mariner, as a representative of a modern man, waits for a savior to rid him of his misery, alienation, and loneliness, but seemingly in vain. In the modernist poetry, the poetic persona struggles to redeem the fragmented and alienated human self. One thing could be the mariner's savior: the rebirth of a new albatross, which can be a metaphorical power of redemption for the former. LauroMeller (2016) describes the mariner's ship as a ghost that carries "death" and "life-in-death," in which the Mariner is saved and the crew is sacrificed. Finally, the mariner blessesand praises God's creatures perceived to him under the moonlight, then the damn of the ship and the crew is expiated and the mariner is able to return safely to his home.

Despite that modernism rejects the romantic allusive ideas and ideals, many critics view the poem as a "supernaturalized world" of the mariner's poetic narrative from a modern perspective (McQueen, 2014, p. 21). Coleridge's rime relies heavily on modern subjectivity that revolves around an alienated and lost mariner with internal and external conflicts. The wholescene relatively implies human drought that results in continuous suffering that haunts human life. For example, this theme is reflected in the moment when the marinerbites his hand to moisten his dark lips with his own blood so that he can palliativelyscream,

And every tongue, through utter drought,

Was withered at the root;

We could not speak, no more than if

We had been choked with soot. (II.33)

Shooting the albatross, the mariner is convicted to an absurd life-in-death, manifesting the human modern life of the lost generation and subjectively passes through various stages of suffering after killing albatross. For Heim Skemman (2016) both the mariner and the wedding guest experience a cycle of torturing alienation that exposes such characters to inescapable death. In addition, Coleridge capitalized his poetic narrative and "modernized his word choice" to better depict the absurd world of the mariner (McQueen, 2014, p. 31). Coleridge puts both the mariner and the wedding guest in a modern whirling crucible with alienation, loss, skepticism, misery, and exile. In the first phase, he suffers severe dryness and thirst, as a punishment which he shares with the crew,

We could nor laugh nor wail;

Through utter drouth all dumb we stood!

I bit my arm, I sucked the bloo.

(III, L. 15-17)

In its modern flavor, Coleridge's poetic discourse revolts to highlight a "greater individual freedoms" (Joavani, 2014, p. 76). In this way, Coleridge evokes and juxtaposes a variety of modernist philosophical, aesthetic, and contemplative natural images to search for human unity and stability, and purgation. In its modernist poetic creativeness, experimentation is a real embodiment of poetic modernism in which the poet devises new expressionist methods that effectively express his creative human experience. The modernist poet utilizes such experimentation methods that include paradoxes and their poetic and contextual tensions. The techniques of experimentation enable the modernist poets to diversely evoke surrealistic images as objective correlatives of modern sense.

Furthermore, Coleridge evokes mysterious subjective implications regarding human misery and instability and keeps depicting the mariner's psychological suffering of a pseudo hope,

One after one, by the star-dogged moon,

Too quick for groan or sigh,

Each turned his face with ghastly pang,

And cursed me with his eye. (III, L. 68-72).

In this sense, Rider indicates that Coleridge's poetics invite postmodern scholars to explore human modern "fierce individuality" (1999). After his experience, the mariner is intimidated and unable to return to his ordinary society. For example, the idea of going to a wedding is an abhorrent idea to him. The most vulnerable point in the poetic narrativeis the moment he is left alone standing on the ship and suffers from the looks of the dead men who besetand curse him. Therein lies the main theme of the poem: isolation or solitude. Coleridge expresses such moments in, 
And through the drifts the snowy clifts

Did send a dismal sheen:

Nor shapes of men nor beasts we ken -

The ice was all between.

Here, these lines constitute a moment of suspense when the mariner stands alone on the ship and suffers the imprecating stares of the corpses. In this view, Pedro B. Gonzalez (1999) views a vivid ... redemptive imagery" that includes two females representing both death and death-in-life. In this respect, the mariner undergoes a redemptive process by atoning for his great sin. The world around him is very wide, but it seems an immense burden that rushes before his eyes. For Weng, the mariner dwells in a "new world of modernity and disenchantment," in which his killing of albatross signifies "senselessness" or meaninglessness of human life. Here, the poem embodies a realistic state of modernity in calamity that the mariner should pay for (2013, p. 144). The mariner is incredibly alone, and curse lurking in the eyes of the crew haunts him and makes him slam all the doors in the face of the world:

... those dead men rise.

$[\ldots]$

The mariners all 'gan work the ropes,

Where they were wont to do;

They raised their limbs like lifeless tools-

We were a ghastly crew.

\section{(V, L. 43-49)}

In their thematic allusive scene, these lines signify that human modern world is trapped by fences of confusion, estrangement, and lifelessness. Relevantly, modernism raises the question of skepticism of reason, revelation, religion, societal morality and values. FengGuo (2016) argues that Coleridge's philosophical poetics intensively present a true mural of the rapport between human and nonhuman, between "the alienated human nature and the redemptive possibility of human relationship in the real world" (p. 2). The mariner suffers a lot of his sin and awakens the feelings of scare and pity of the public readers. Martin Gardner (1999) states that Coleridge's poem arouses a variety of fears that trap modern world, in which there is an awfully silent "rotting" ocean that challenges a "universe of a modern naturalist," stained with transcendent absurdity and totalitarian nihilism (p. 14). Nevertheless, Coleridge emphasizes the idea of life-in-death, or death-in-life, in which the mariner's act is not a barbarous act; it is viewed as a usual sin that any ordinary man can commit. The albatross around the mariner's neck manifests the burden of his sins; it falls away when the mariner repents and atones for his sin, he also blesses the marine snakes. In this sense, one of the most significantly influential features of modernism is the technique of symbolic intertextuality as in the hanging of the bird in the mariner's neck. Such an ex example evokes religious thematic intertextuality with the Quran, "Every man's fate We have fastened on his own neck" (Chapter 17, Surat Al-Isra-The Night Journey- Al-Quran). This technique supports Coleridge's idea of sinning and punishment in a diachronical modernist sense.

Furthermore, the poetic narrative undergoes certain thematic and suggestive transformations and shifts. For instance, the most significant transformation is the shift from a stupid, idiot, and arrogant character who hates large birds into a character whose soul is pious and godly even for uglier creatures. Another example of modernist intertextuality in Coleridge's poetics is the evocation of the tale of the Sinbad, the sailor that intertextualizes what happens to the old mariner in the sea. In fact, such techniques of interdisciplinary intertextuality and acculturation are modernist; both evoke ideas or concepts from other disciplines and cultures, whether they are religious, historical, scientific, cultural, and philosophical. Thus, intertextual symbolism is a modernist technique, in which modernist poets try to domesticate their poetic texts. This rhetorical technique is a fertilizer that bestows significant pluralism on poetic texts and offers them intellectual enrichment and profound cognition. In Coleridge's poem, there are several instances of poetic thematic symbols that deepen the modernist part of the text. For instance, the albatross is a haunting code that metaphorically raises a variety of matters and questions before the mariner and the crew of the ship regarding human life and miseries. Graham Perchey (2009) views the bird as a symbol that implies a "transcendental synecdoche," which makes the absence in modern man a good omen, which breaks the link between the natural and the supernatural. Here, this poetic image is likely the most prominent and famous in this poem,

Her locks were yellow as gold:

Her skin was as white as leprosy,

The nightmare Life-in-Death was she,

Who thicks man's blood with cold.

(III, L. 48-52)

The fate of the ancient mariner is determined accidently: he will either die or live a life immensely like death. In addition, Coleridge presents poetical images that perceive various human senses and feelings. Joavani (2014) views a sort of poetic personifications of death and life-in-death, in which "death's mate wins over the 
mariner" (p. 83). In this regard, Coleridge says, "Is that a Death? and are there two? Is Death that woman's mate?" (III, L. 46-47). Modern man can survive a lot of dilemmas and troubles amidst confusion and bewilderness, in which people, like the mariner, sin and eventually meet fate of life-in-death. Obviously, life-indeath is one of the authentic mythological innovations in the poem:

A spring of love gushed from my heart,

$\ldots$

Sure my kind saint took pity on me,

And I blessed them unaware. (IV, L. 61-64)

In its juxtaposing theme, the fall of albatross from the neck into the depth of the sea symbolizesthe end of the mariner's heaviest burden. In this respect, transformation from an individual experience to a collective one is another key feature of modernist poetry. After killing the albatross, the mariner transforms from a jubilant chump who despises huge birds to a devout soul who prays for the repugnant creatures,

And now this spell was snapped: once more

I viewed the ocean green,

And looked far forth, yet little saw

Of what had else been seen- $\quad$ (VI, L. 33-36)

We're not exactly sure why the sailors' curse is broken at this exact moment, but it relates somehow to his earlier blessing of the sea snakes. Immediately the ocean turns from a sickly blood red to its normal color, bright green. Also, after hearing the narrative of the mariner, the wedding guest transforms; he understands that life is not all fun and happiness and gets mysteriously wiser,

He went like one that hath been stunned,

And is of sense forlorn:

A sadder and a wiser man,

He rose the morrow morn.

(VII, L. 108-111)

As such, Coleridge offers us a modernist poetic view to understand the human and nonhuman worlds and reflect on human idiosyncratic experiences. The greatest moment of transformation of the old mariner is when he realizes that even the weakest and strongest creatures are worthy of love and blessing. Like a modern man, Coleridge's mariner undergoes a project of adventures fused with a lot of scare, gratification, comedy, and tragedy. In its thematic sense, Coleridge employs retribution as a mirror through which the direst state of physical and psychic loneliness is reflected.

Apparently, Coleridge envisages a modern human voyage featured with alienation, confusion, selfpunishment, agony and loneliness. After sinning, loneliness dominates the life of the mariner and his poetic metaphorical cruise manifested in his misery, passions, and drought. For Jenny L. Davis (2012), Coleridge expresses his concept of human alienation in the dispute between reality and appearance, resulting in a state of "defamiliarizing effects of grief of the crew and the mariner (Davis, 2012, p. 12). Thus, Coleridge manifests the idea of fragmentation of the human self of the mariner who sins and faces both earthly and divine punishment (Davis, 2012, p. 22). However, the direct curse of albatross has been lifted and the mariner starts living life-indeath in a redemptive way. In this respect, Moulin (2005) states that Coleridge's poetics signify a reconciliatory project of "modern problem of the Self" (p. 5). Yet, the mariner cannot really wipe away the results of his action, as a result he must permanently reiterate his transformation into another modest character. He wants the hermit to make him admit his ugly deed:

He singeth loud his godly hymns

That he makes in the wood.

He'll shrieve my soul, he'll wash away

The albatross's blood

(VI, L. 98-101)

In this respect, the mariner's poetic narrative exemplifies "a perverse satisfaction in rebelling against the growing, often ugly, complexities of modern life" (Gardner, 1999, p. 105). This is the reason that the wedding guest recognizes that human kind is certain about the thing that makes humanity wiser; it is one of the poetical mysteries. Skemman (2016) argues that the scene of the wedding guest's youthfulness signifies the future and anticipates "the modern secularization that has become apparent in today's world." At this moment, the mariner loses his mind and temper,

He went like one that hath been stunned,

And is of sense forlorn:

A sadder and a wiser man,

He rose the morrow morn.

(VII, L. 108-111) 
Thus, the old mariner, despite being alive and that he might not pass away in a sense, speaks beyond the grave to warn others of the dire consequences of the moments of stupidity, selfishness, and lack of respect for the natural world. For Strongman, Coleridge anthropomorphizes nature and its indifference as qualities of absurdity and/or "nihilism" that constitute a challenge for mass readers (2009, p. 70). Hence, Coleridge actualizes modernist thematics that show a qualifying characteristic of modernist poetics. Thematically, the poem immensely uses modernist narrative formalistic techniques such as ironies, juxtaposition, displacement, allusions, symbols, and signs. To substantiate, the mariner depicts a water image, "Water, water, every where, Nor any drop to drink" that implies a situational irony, in which the moment of being in the middle of the sea water, the mariners cannot drink for some reason (II, L. 37). Thus, the rime embodies a significant feature of modernism that centers on human self-consciousness and multifaceted confusion. For example, the title has a confusing pun in the word rime, which may parallel the word rhyme that means the poetic device. Coleridge expresses his poetic vision of modern man, who is confused and alienated and searches for "a mythical place" to find a refuge and amity (Meller, 1999). Moreover, the word rime means chillness, especially that ofthefrost out of cold fog and wind. Along with this technique of confusing irony, Coleridge uses paradoxes, in a modernist sense, to deliver multifaceted significant values that release profound meanings and significances which bear themato-poetic insights. For example:

Her beams be mocked the sultry main,

Like April hoar-frost spread;

But where the ship's huge shadow lay,

The charmèd water burnt alway

A still and awful red.

(IV, L. 267-271)

This conceited image of the moon emits bleak colors on the ship, yet, the water enlightens the red in its shade. Paradoxically, the moon may quill the curse shortly, but it still reposes underneath. Meanwhile, the moon and the sun play poetic significant symbols in this poem. The sun implies God's grumpy power; yet, the moon has a more favorable signification than the sun. Generally, hardships arise to the Mariner during the sun-day, while favorable happenings arise by moon light.

The modernist aesthetic features of the poem do not arise only from its moral significance, which looks unconvincing at times. Rather, this poetic moral significance lies in the exclusive poetic details manifested in the signifying images and the flow of emotions, in a deeply dark horizon with deep chillness and feelings of guilt. Coleridge uses poetic stream of consciousness to expose what happens in the mariner's own mind. The mariner expresses his own internal feelings of isolation and fragmentation to the wedding-guest to help release his tension and passions after killing an innocent bird,

O Wedding-Guest! this soul hath been

Alone on a wide wide sea:

So lonely 'twas, that God himself

Scarce seemed there to be.

(VII, L. 84-87)

Here, the lines characterize as dramatic monologue in which that the mariner expresses his deep feeling of loneliness and frustration and evokes the juxtaposed images of the wedding-guest, sea, and God. This dramatic moment signifies Coleridge's stream of consciousness that allows him to experiment in his techniques that exemplifies early modernist flavor. Moreover, this technique also enables the mariner to challenge the various facets of the modern world. These aspects of life are very different from the elements of nature obsessed over by pre-modern Romantic poets. Harold Bloom (2001) argues that Coleridge has written poetics that belong to modernism stained with poetic subjectivity and "sense of guilt and of self-abnegation" (p. 9). Then, Coleridge offers his own vision of modern man who challenges theantithetic argumentations of modern subjectivity and its skepticism, alienation, and mortification. Metaphorically and cognitively, the sea in the mariner's life is mysterious as it becomes "a place of isolation, alienation and loneliness" (Skemman, 2016). Thus, this view implies a modernist conceptualization of the sea as a place that provokes human feelings of fragmentation, estrangement, and solitude. Such evocation delivers an idea that touches the symbolic emotional and mystical synonymous dimensions of the sea, which include rebirth and creation. The mariner is trapped by a fence of subjectivity fused with lack of "fragmentation and reinforced isolation" (Davis, 2012, p. 8). The poetic discourse implies that killing the bird is a crime against creation as a whole and that the influence of sin is rooted in the depths of the poetic persona.

Furthermore, Coleridge's poem involves "fragments of truth" that imply a mistaken viewpoint based on the pragmatic human experience, the poetic discourse here is meant to rediscover such fragments aiming at the entire truth that vindicates the said fragments (McGann, 1981, p. 52). Accordingly, the mariner is mystified by his original guilt which makes him think that the ocean is "a death-trap, a watery prison of the soul" (Gonzalez, 1999) in which there is "Water, water, every where" (II, L.37). In its modernist implication, the water around 
the sailors is timid and absurd for the mariner's physical and intellectual metamorphosis is not mature to purge the place and the people of the intensified human drought. Coleridge's poetics in the rime arouse "philosophical existentialism," in which the mariner suffers from a senseless nature of human life, which embodies features of absurdity (Skemman, 2016). The event of killing the bird seems like having the forbidden apple from theParadise by Adam. In its human modernist sense, the mariner is like Adam; both caused humanity a lot of burdens that both should atone and purge themselves of the burdened human sin. Therefore, Coleridge's mariner is a poetically grand thematic symbol of modern human "self-consistent metaphorical level" of all men, loaded with sins (Gardner, 1999, p. 16). In this light, the poem represents a recapitulation of the utmost human creative thought which confessespantheism thatrepresents the Creator and His creation.

Critics view this poem as the most complete fantastically modernized creative text in English poetry. Moulin (2005) argues that Coleridge offers poetics that imply the "ancestor of modernist collage and montage" (p. 8). Thus, Coleridge delivers a poem characterized with a transparentsoul, a creative vision, and a brilliant and aesthetic poetic style. Coleridge's poetic mural presents supernatural and romantic characters who show modernized human truth charged with "poetic faith" (Joavani, 2014, p. 77). Meanwhile, the poet transfers the reader from reality into a world of fantasy and charm located between dream and reality; this poem is a rich representative of such poetic narrative discourse charged with interior musicality, prelusion, alliteration, anaphora, and antithesis. Coleridge uses alliterations to add musical palliative vivacity to his poetics in its modernist sense. For example, he says, "The breezes blew, the white foam flew, The furrow follow'd free," in which the bold letter sounds are examples of alliteration (II, L. 21-22). Similarly, the poet uses anaphora in "Below the Kirk, below the Hill, Below the Light-house top" to create a sort of invocation in musicality that manifests a modernist feature (I, L. 22-23). Thus, Coleridge's poetical mural is fused with the mystical that "transcends and frustrates [human] forceful empirical explanations" of past and modern human reality (Gonzalez, 2015).Yet, the poet seems to orientate his modern readers into a realm charged with questions and wonders. Coleridge's narrative poem has a true modernized "supernatural plot" that seems thematically "archaic and modern" (Weng, 2013, p. 141). Therefore, readers should not look for one specific final meaning for the poem; they should view it as a profound human significant poetic story, aesthetically and thematically exciting and entertaining. Moreover, Coleridge's poetic structure is based on "the archaic diction of the ballad, but equally important is the modern diction" (McGann, 1981, p. 58). Generally, such an archaic poetic discourse is thematically significant to modern commonplace language. Accordingly, the poem draws on a unique and exciting aesthetic experience; it is a multifaceted poem, in which such facets complement one another. Coleridge's poetic discourse expresses man's uncertainties and enthralls human nerves and challenges human soul.

Again, the attitudinal transformation in the poem raises a variety of questions about modern man's ability to create an ethical system out of the laws of nature, art, and natural sciences thatare separated from the sole value. In this regard, Jerry Ch. Weng (2013) argues that the mariner's voyage signifies the descendance into "knowledge and self-consciousness of modern existence" intimidated by two awful bodies on the ship: death and life-in-death (Weng, 2013, p. 143). In other words, knowledge provides humanity with moral standards that enable people to distinguish between good and evil, justice and injustice. For Bloom, the mariner undergoes "a spiritual rebirth," signifying an instance of cognitive transformation in his own realization of the dangers and threats around him (2001, p. 18). Accordingly, such relative transformation is an epistemological base of human community and a moral foundation to individuals.

In its modern sense, Coleridge's poetic mural offers a set of "moral idea in life, theory and poetry based on freedom and alienation, the responsibility, self-evolution and English moral tradition" (Guo, 2016, p. 5). Furthermore, the poem has its own thematic and significant "modern context" in which nature plays a major role in shaping the thematic path of Coleridge's poetics and arouses his capacity of imaginations and contemplation out of despair and alienation (Rider, 1999). In this respect, modernist imagism enriches the poetic scene that enables readers to realistically visualize and experience the poet's discourse. Imagery arouses human sensations of sight, taste, smell, touch, and hearing. For example, Coleridge says,

The ice was all around:

It cracked and growled, and roared and howled,

Like noises in a sound! (I, L. 59-61)

These imagist lines invoke human senses of sight and hearing, for the ice is visualized as cracking, growling, roaring, and howling sounds. Similarly, Coleridge's poem evokes poetic surrealistic images thatemphasize his anticipatory modern imagination. Obviously, critics have explored the possible modern aesthetic and thematic features of the poem; its fertile poetic space and mythical tone that suggest the intrinsic ability of man to transcend to wide folds of human knowledge based on meditation, experience, inquiry, and contemplation.

Moreover, displacement of images and symbols is a modernist technique Coleridge uses to offer the reader a variety of significant thematic options. For instance, Coleridge displaces the moon with a ghostly bark, 
The sun's rim dips; the stars rush out:

At one stride comes the dark;

with far-heard whisper, o'er the sea,

Off shot the spectre bark.

Here, the Mariner's universe starts reorganizing itself through displacing the metonymic bark with the metaphoric moon that causes the death of the other mariners. Thematically, the moon also displaces the sun to change the poetic tone. Accordingly, visual imagery penetrates modernist poetic texts under the technique of experimentation, offering wider spaces to invent unfamiliar forms that parallel renewed structures. This imagist technique is manifested in Coleridge's significant modernist poetic narrative. In addition, the mariner admits shooting the albatross, making the displacement of the cross from his neck:

Ah wel-a-day! what evil looks

Had I from old and young;

Instead of the Cross the Albatross

About my neck was hung. (II, L. 57-60)

Here, Coleridge juxtaposes the natural and the human, where the metaphysical is fused with the realistic such as in life-in-death death, using man-made tools like the ships and the dice. Such poetic juxtaposition is a serious indicative feature in Coleridge's poem, he says,

The death-fires danced at night;

The water, like a witch's oils,

Burnt green, and blue and white.

(II, L. 46-48)

Here, Coleridge fuses and juxtaposes religious, gothic, and cryptic figures. Like in these lines, juxtaposed images bounce between life and death representing both salvation and damnation of the mariner respectively. Thus, image displacement is significant to enrich the poem's thematic, cognitive, and artistic layers. Accordingly, poetic modernism is thematically and artistically manifested in the form and content of the poem. Ostensibly, the poetic discourse has a structural form, creating an organic unity that controls the content and the thematic space, a thing that grants the poem its modernist aspects.

On a larger scale, Coleridge thematically uses "a transcendental philosophy" to project modern ideologies (Perchey, 2009). It is also an impressionist portrait about the diachronical experience of the whole humanity in all times and places, characterized by philosophical and psychological depths that refer to the transformation of the mariner from a materialist person to a person of a deeper awareness of the beauty of nature and itssignificance. In this sense, Shawn Rider (1999) argues that imagination yields "a higher quality verse" that creates fresh modernized ideas that signify "the balance or reconciliation of opposite or discordant qualities." Meanwhile, the poem is an expressionist view of the mistaking human soul and a confirmation of the structural body of the world and the failure of automated human materialist mind to understand and perceive the realistic things around it.

In the light of the previous formalistic analysis, the most important thematic characteristics of modernism that dominate the space of Coleridge's poem include confusion, skepticism, anxiety, alienation, escapism form reality to killing, challenges, and adventures. They also include challenging the traditional, overstepping the boring stereotypical norms, innovation in language; its structures, imagery, and techniques. Coleridge employs such techniques to expose human coincidence, luck, obsession, and imagination and to address the psychological and intellectual manifestations of the failure of human mind to face reality. The poem also includes modernist aspects embodied in the revolution against nature, the universe and its regime, and the demonstration of modern human who can defeat nature or at least challenge it.

\section{CONCLUSION}

Coleridge precedes the modernist poet in reading human existence from within through things around his soul and body; it is not an external reading of the universe. Thus, the modernist projects what he sees according to his own perspective and vision on the world. Therefore, Coleridge's poem is full of aesthetics, which create modernist uniqueness, rhetorical questions, anticipation, ambiguity, visionary, and juxtaposition. All of which strengthen the poetic forms torevitalize their signification and semantic and interpretive mechanisms. Such modernist techniques pave the way to the poem towards pluralism, which does not assume a single meaning, but which detects the aesthetics of the modernist poetic text. Accordingly, Coleridge's poetics are composed of exclusiveness and subjectivity that imply a collective representation of modern man expressed by his modernist themes, techniques, and poetic diction. Coleridge's modernist poetics stress the ideas of alienation, fragmentation, and loneliness, all of which are negative features of modern life. His poetics expressthe dilemmas of the modern human kind, represented by the mariner, who elegizes his intellectual and physical flaws and lack of calculation. Finally, Coleridge shows poetical mastery of modernist techniques and 
devices that aestheticize his poetics and influentially expresses his modernist juxtaposed themes and ideas. His poetics are charged with thematic allusions, intertextualities, images, musicality, and symbolism among others.

\section{REFERENCES}

[1] Al-Quran. Retrieved on 12/1/2017 from http://corpus.quran.com/translation.jsp?chapter=17\&verse=13

[2] Bloom, Harold., ed. Modern Critical Interpretations: The Rime of the Ancient Mariner. New York: Chelsea House, 2001.

[3] Davis, Jenny L. (2012). Materializing meaning: Samuel Taylor Coleridge and George Eliot. MA Thesis. University of Chester, United Kingdom. Retrieved on 30/12/2016 from http://hdl.handle.net/10034/269859

[4] Gardner, Martin (1999). Gardner's Whys and Wherefores. New York: Prometheus Books.

[5] González, Pedro B. (2015). "Coleridge's Ancient Mariner and the Faith that Comes by Hearing." Retrieved on 8/8/2016 from http://www.kirkcenter.org/index.php/bookman/article/coleridge-ancientmariner -faith-by-hearing/

[6] Guo, Feng. (2016). "A Literature Review of T. S. Coleridge in China and at Abroad." Studies in Literature and Language. 12 (2): 1-6. Retrieved on 7/82016 from http://www.cscanada.net/index.php/sll/article/view/8170

[7] Joavani, Lourdes J. (2014). “The Interplay of Faith and Imagination: An Analysis of Coleridge's Rime of the Ancient Mariner.” International Journal of Languages and Literatures. Vol. 2, No. 2, pp. 73-97.

[8] McGann, Jerome J. (1981). "The Meaning of the Ancient Mariner." Critical Inquiry. 8(1): pp. 35-67. Retrieved on 5/1/2017 from http://www.jstor.org/stable/1343205

[9] McQueen, Joseph (2014). "Re-enchanted orthodoxy in Coleridge's 'The Eolian Harp' and The Rime of the Ancient Mariner." Christianity and Literature. Vol. 64(1) 21-42

[10] Meller, Lauro (2016). "Coleridge Revisited: Rock Versions of 'The Rime of the Ancient Mariner' and 'KublaKhan'." $\quad$ Retrieved on $31 / 12 / 2016$ from www.leffa.pro.br/tela4/Textos/Textos/Anais/ABRAPUI.../lit56.pdf

[11] Moulin, Joanny (2005). "Remanent Romanticism in Modern Poetry." Cercles. 12: 1-13.

[12] Pechey, Graham (2009). "Crossed Lines: The Vernacular Metaphysics of the Ancient Mariner." $\begin{array}{lllll}\text { Retrieved } \quad \text { Dec } & 25, & 2016 & \text { from }\end{array}$ https://www.thefreelibrary.com/Crossed+lines\%3a+the+vernacular+metaphysics+of+the+Ancient+Marin er.-a0213601770

[13] Rider, Shawn (1999). "Wordsworth and Coleridge: Emotion, Imagination and Complexity." Retrieved on 15/11/2016 from http://www.wdog.com/rider/writings/wordsworth_and_coleridge.htm

[14] Skemman, Heim (2016) "Symbols in Samuel Taylor Coleridge's The Rime of the Ancient Mariner." Retrieved on 6/1/2017 from http//skemman.is/stream/get/1946/4253/12337/2/Meginmalpd_fixed.pdf.

[15] Strongman, Luke (2009). "Captain Cook's Voyages and Coleridge's The Rime of the Ancient Mariner." Junctures: The Journal for Thematic Dialogue. (12): 69-81.

[16] Weng, Jerry Chia-Je (2013). "The Catastrophic Global Order in Samuel Taylor Coleridge's The Rime of the Ancient Mariner.” Waseda RILAS Journal. 2013, volume: 1, pp. 141-145. 